\title{
EL hOMBRE TECNOLÓgICO COMO FETICHE DE LA MODERNIDAD AMPLIADA. ACUERDOS Y DESACUERDOS CON LA POSMODERNIDAD COMO RESISTENCIA DE JESÚS BALLESTEROS
}

\author{
The Technological Man as a \\ FETISH OF EXTENDED MODERNITY. \\ AgreEMENTS AND DISAgREEMENTS WITH \\ Posmodernity as Resistance, By \\ Jesus Ballesteros
}

O HOMEM TECNOLÓGICO COMO FETICHE DA MODERNIDADE AMPLIADA. ACORDOS E DESACORDOS COM A PÓS-MODERNIDADE COMO RESISTÊNCIA, DE JESÚS BaLLEsteros

JOSÉ ANTONIO SANTOS* * $\quad$ orcid.org/0000-0003-0057-7822. Universidad Rey Juan Carlos . España.
joseantonio.santos@urjc.es

RECIBIDO: 27 DE MARZO DE 2016. ENVÍO A PARES: O4 DE AGOSTO DE 2016 APROBADO POR PARES: 26 DE ENERO DE 2017. ACEPTADO: O5 DE MARZO DE 2017

DOI: $10.5294 / D I K A .2017 .26 .1 .2$

PARA CITAR ESTE ARTí́CULO / TO REFERENCE THIS ARTICLE / PARA CITAR ESTE ARTIGO JOSÉ ANTONIO SANTOS. "EL HOMBRE TECNOLÓGICO COMO FETICHE DE LA MODERNIDAD AMPLIADA. ACUERDOS Y DESACUERDOS CON LA POSMODERNIDAD COMO RESISTENCIA DE JESÚS 


\section{RESUMEN}

El presente artículo señala que nos encontramos en un mundo hipertecnológico, en el que todo es incierto y relativo dentro del contexto de la modernidad ampliada. Este punto de partida sirve para analizar cómo el capitalismo y el individualismo radicales han propiciado una imagen decadente del hombre tecnológico, una situación que muestra el triunfo del materialismo y la decadencia de los valores culturales, éticos y jurídicos en relación con la comprensión del transhumanismo. En la actualidad, el ser humano es un hombre casi aislado y la naturaleza humana resulta líquida, por lo que se hace necesario abogar por un nuevo concepto, más acorde con el respeto al ser humano, que no empobrezca las relaciones humanas. Por ello, este panorama sirve para establecer un diálogo con la posmodernidad como resistencia, de Jesús Ballesteros, como forma de lucha para responder a la injusticia, la inhumanidad y el cretinismo progresivo del mundo actual. Al mismo tiempo, se realiza un pequeño esbozo de una ética jurídica del débil que sirva como alternativa a la actual imagen tecnológica del hombre. Una concepción que persigue dejar una mejor humanidad para las generaciones futuras desde el punto de vista ético y jurídico.

\section{PALABRAS CLAVE}

Biotecnologia; individualismo; naturaleza; posmodernidad; transhumanismo. 


\section{ABSTRACT}

The article says we are in a hyper-technological world where everything is uncertain and relative within the context of extended modernity. This point of departure serves to analyze how radical capitalism and individualism have led to a decadent image of technological man, a situation that illustrates the triumph of materialism and the decline of cultural, ethical and legal values in relation to the understanding of transhumanism. Nowadays, the human being is an almost isolated man and human nature is liquid, which is why it is necessary to advocate a new concept, one that is more in line with respect for the human being and does not impoverish human relations. Hence, this view serves to establish a dialogue with postmodernism as resistance, according to Jesús Ballesteros; that is, as a form of struggle to respond to the injustice, inhumanity and progressive senselessness of today's world. A brief outline of a legal ethic of the weak is provided as well to serve as an alternative to the current technological image of man. It is a perception that seeks to provide a better form of humanity for future generations, from an ethical and legal point of view.

\section{KEYWORDS}

Biotechnology; individualism; nature; postmodernity; transhumanism. 


\section{RESUMO}

Este artigo demonstra que nos encontramos num mundo hipertecnológico no qual tudo é incerto e relativo dentro do contexto da modernidade ampliada. Esse ponto de partida serve para analisar como o capitalismo e o individualismo radicais têm propiciado uma imagem decadente do homem tecnológico, uma situação que mostra o triunfo do materialismo e da decadência dos valores culturais, éticos e jurídicos em relação à compreensão do transumanismo. Na atualidade, o ser humano é um homem quase isolado, e a natureza humana se torna líquida, razão pela qual se faz necessário advogar por um novo conceito, que esteja mais de acordo com o respeito ao ser humano, que não empobreça as relações humanas. Por isso, esse panorama serve para estabelecer um diálogo com a pós-modernidade como resistência, de Jesús Ballesteros, como forma de luta para responder à injustiça, à desumanidade e ao cretinismo progressivo do mundo atual. Ao mesmo tempo, realiza-se um pequeno esboço de uma ética jurídica do fraco que sirva como alternativa para a atual imagem tecnológica do homem. Uma concepção que pretende deixar uma melhor humanidade para as gerações vindouras do ponto de vista ético e jurídico.

\section{PALAVRAS-CHAVE}

Biotecnologia; individualismo; natureza; pós-modernidade; transumanismo. 
Sumario: INTRODUCCIÓN; 1. LA VIEJA Y LA NUEVA MODERNIDAD; 1.1. LA MODERNIDAD AMPLIADA: DECADENCIA A ESPALdAS DEL SER HUMANO; 1.2. CRISIS DE LA RAZÓN JURÍdICA EN TIEMPOS DE DEMOCRACIA; 2. EL HOMBRE TECNOLÓgICO Y SU DEVOCIÓN INDIVIDUALISTA Y CAPITALISTA; 2. 1. LA NUEVA IMAGEN DEL HOMBRE: UN SER CASI AISLADO Y POCO COMUNICATIVO; 2.2. DECADENCIA Y MERCANTILIZACIÓN DE las Relaciones humanas; 3. Naturaleza humana líquida y la NUEVa era de las máquinas; 4. Conclusiones; Bibliografía.

\section{INTRODUCCIÓN}

En la actualidad vivimos tiempos en los que todo es incierto, relativo, no hay nada seguro: no hay verdades vigentes, todo suena posmoderno. Las ideas y creencias milenarias en que descansaban las sociedades occidentales parecen haberse evaporado, ocupando su lugar nuevas ideas y creencias, en ocasiones fugaces. No pocas de ellas se han ido desarrollando al compás de las nuevas tecnologías y acrecentándose con una crisis global en diferentes planos. Como dice Serna, con "la sensación de estar viviendo tiempos difíciles, tiempos de crisis en el sentido originario de cambio desde un mundo que agoniza hacia otro que aún no sabemos exactamente cómo será ni el papel que nos tocará desempeñar en él, si es que hay en él algún papel reservado para nosotros". ${ }^{1}$ Ya estamos inmersos en el cambio de era, en un periodo de transición hacia un nuevo orden todavía no consolidado. La erosión de los valores culturales, éticos y jurídicos ha dado paso a la prioridad en favor de aquellos de carácter estético y económico.

Hoy nos encontramos ante una nueva modernidad que no deja de parecerse a la vieja en elementos tan cruciales como el individualismo y el capitalismo radicales y feroces, insertos en un contexto tecnológico que determina una nueva concepción del ser humano. Este radical cambio surte efecto sobre la nueva imagen del hombre tecnológico que opera en el terreno de una modernidad ampliada, rupturista con lo mejor de nuestro pasado, siendo uno de sus escenarios paradigmáticos la manipulación genética. La modernidad ampliada puede entenderse como aquel periodo histórico, sociológico y filosófico, entendido en sentido amplio, caracterizado por un fuerte individualismo, economicismo, tecnologismo y racionalismo desarrollado en un contexto falsamente globalizado. Es ampliada por su condición de ser heredera de la vieja modernidad y por la razón de todavia no estar concluida. La presencia destacada de uno de los "ismos", el tecnologismo, refleja una imagen del hombre con una faz desvirtuada y decadente, que muestra la posibilidad de soñar con mundos mejores y, a la vez, contribuye a mostrar la peor imagen del resto de "ismos". Una posibilidad que no puede más que generarnos una actitud de sospecha ante un presente engañoso y un futuro incierto que vislumbra una nueva imagen del hombre, particularmente en el ámbito (bio)tecnológico, aunque no solo en él. Campo en el que cobra especial relevancia la lucha por revitalizar un concepto de naturaleza humana más acorde con el respeto por el ser humano y no uno como el actual que empobrece, por medio del transhumanismo, las relaciones humanas.

1 Pedro Serna, "Política posmoderna y crisis de la razón jurídica", en Anuario da Facultade de Dereito da Universidade da Coruña 13 (2009), p. 1081. 
Una vez hechas estas aseveraciones conviene explicar también en qué consistirian los acuerdos y los desacuerdos con Jesús Ballesteros, a fin de contextualizar el desarrollo del trabajo. Los acuerdos con el pensamiento de nuestro autor vienen motivados por la asunción en su filosofía del derecho de una ética jurídica del débil $^{2}$ que, a grandes rasgos, se comparte, sin perjuicio de que se difiera en algunos a priori importantes utilizados por el autor, dado que las influencias son en buena medida diferentes. En su caso, presenta una mayor influencia francesa y de la doctrina social de la Iglesia; mientras que aquí suscribimos una perspectiva más germánica y cercana a propuestas estoicistas.

Resulta destacable su intención de construir una filosofia del derecho que encierre una ética jurídica como cuidado del débil, cuya finalidad es no hacer prevalecer sistemáticamente los intereses de los fuertes frente a las necesidades de los débiles. El acuerdo con Ballesteros, también aparece en su escepticismo en relación con el futuro, que no refleja una postura temerosa, sino de compromiso con el actual tiempo histórico. A la nota de compromiso habria que añadir su constante intención de repensar el tiempo presente, que refleja a las claras su decidida tarea de pensar en los demás.

En relación con todo ello, cabe destacar lo que puede considerarse como una simplificación acerca del pensamiento jurídico-filosófico de Ballesteros. En contra de lo que pueda parecer, él no desarrolla en el fondo un pensamiento de carácter conservador, aunque él sí lo sea en sus hábitos, en la postura sostenida respecto de algunos temas y por la influencia de la doctrina social de la Iglesia. ${ }^{3}$ Más aún, no es conservador en el sentido inmovilista y estático del término, sino innovador y dinámico; en especial, si uno se acerca a su obra Postmodernidad: decadencia o resistencia ${ }^{4}$ como eje vertebrador de otras publicaciones posteriores.

A lo largo de estas líneas, el análisis se centra más en los múltiples acuerdos que en los pocos desacuerdos (sin perjuicio de que algunos salgan a la luz), por la sencilla razón de que el objetivo consiste en cuestionar, someter a crítica y advertir de la deriva tomada en la sociedad contemporánea, en lo referido al respeto por el ser humano y a la confianza extrema en la tecnologia ${ }^{5}$ como medio para solucio-

2 En cierta medida, también se podría hablar de la defensa de una ética del oprimido por su referencia a los marginados.

3 Hasta el punto de que a su filosofia jurídica subyace toda una antropología cristiana. Desde sus primeras publicaciones se detecta en Ballesteros la influencia de los padres de la Iglesia, de la metafísica tomista y de la fenomenología existencial. Buena prueba de ello es su tesis doctoral, en formato de libro, titulada La filosofia jurídica de Giuseppe Capograssi, Roma-Madrid, CSIC, 1973.

4 Jesús Ballesteros, Postmodernidad: decadencia o resistencia, Madrid, Tecnos, 1989. En adelante citamos por la $2^{\text {a }}$ edición, Madrid, Tecnos, 2000.

5 Si bien no es una cuestión pacífica, consideramos más apropiado el término tecnología que el de técnica pues implica un conocimiento metódico, descriptivo y causal de lo que se pretende conseguir, además de una relación directa con los conocimientos científicos del momento. Con el paso del tiempo, la tecnología puede convertirse en técnica al quedar desfasados los conocimientos científicos que la sustentaban total o parcialmente. Es decir, se ha pasado a un intento de concreción al milímetro, no solo de los saberes, sino también de las cosas. La excesiva concreción ha hecho perder perspectiva, José Antonio SANTos, Los olvidados del nacionalsocialismo. Repensar la memoria, Madrid, Centro de Estudios Políticos y Constitucionales, 2014, p. 162. 
nar problemas jurídicos y éticos del presente. Suscita interés la posmodernidad en tanto resistencia de Ballesteros como forma de lucha bastante aceptable para responder a la injusticia, inhumanidad y cretinismo progresivo del mundo actual en el contexto de la modernidad ampliada. Es sabido que detrás de toda fundamentación jurídica y ética subyace una concepción antropológica que es preciso explicitar, a fin de entender los derroteros por los que fluirán los diversos planteamientos acerca del derecho y la ética. Esto hace que se entremezclen deliberadamente los argumentos antropológicos, éticos y jurídicos. De esta manera de resistir nos interesa especialmente su lucha frente a la indiferencia individualista y al despilfarro consumista. ${ }^{6} \mathrm{El}$ autor no se conforma con la situación actual, sino que pretende ir más allá de los tópicos y estereotipos vigentes con una visión proteccionista de todo ser humano. Concepciones de este tipo pretenden dejar una mejor humanidad para las generaciones venideras y posibilitar un futuro más auténtico desde el punto de vista ético y jurídico. En este contexto, debemos ser conscientes de que cuanto más distante y difuso sea el fin: dejar un futuro estable para la humanidad, mayor será la exigencia de justificación.

\section{LA VIEJA Y LA NUEVA MODERNIDAD}

Situarse por un momento en la modernidad tiene su sentido para explicar que, en aspectos como el culto al consumismo, el afán calculante del racionalismo exacerbado y el excesivo apego a las propuestas individualistas que dejan poco margen al papel de la comunidad, observamos una mayor linealidad en la transición de la modernidad a la posmodernidad. Tales aspectos, unidos en su versión extrema, fácilmente pueden ser considerados negativos a nuestros ojos. Esta idea, sin embargo, no resta importancia a los relevantes hechos históricos acontecidos durante la modernidad, ni a los grandes logros alcanzados, como tampoco a los aspectos positivos del capitalismo (sostenimiento de libertades individuales, generación de riqueza, propiedad privada, etc.), el racionalismo (mejora en el conocimiento cierto y evidente de la realidad, profundización en la verdad empírica y en la formal, etc.), y del individualismo (desarrollo de la personalidad del individuo, reconocimiento de derechos individuales, delimitación del interés individual, etc.). Es cierto que no haríamos justicia a los dos conceptos si no matizara a cuál de ellos hacemos referencia aquí. Hablamos del individualismo triunfante en contraposición al postergado, por utilizar la distinción de Julios Campuzano; es decir, el "individualismo capitalista del laissez faire que triunfó fácticamente desde los inicios del industrialismo y supuso el sometimiento de la clase obrera a los intereses económicos de la burguesía y de los terratenientes". En la otra cara de la moneda se encontraba el individualismo liberal de carácter más humanizado, que "vino a ver en cada individuo un sujeto moral y que hizo depender el progreso social de la efectiva realización del ideal de autonomía”, ${ }^{7}$ llegando a cimentar

6 Combatidos por Ballesteros desde la solidaridad ecuménica y la frugalidad ecológica, Jesús BALLEsteros, Postmodernidad, op. cit., p. 13. En esta ocasión no centraremos la atención en estos dos conceptos, de modo que el análisis versará sobre las ideas marco de su concepción.

7 Alfonso de Julios CAMPuZano, "Individualismo y modernidad. Una lectura alternativa”, en Anuario de filosofia del derecho, XII (1995), p. 240. 
declaraciones como la de Independencia de Estados Unidos o la de los Derechos del Hombre y del Ciudadano.

Los fenómenos del individualismo, el racionalismo y el capitalismo fueron esbozados en el Renacimiento, consolidados en la Ilustración y acrecentados en el transcurso del Romanticismo. Durante estos periodos de tiempo son relevantes tres pensadores y obras que marcan en buena medida el espíritu del pensamiento posterior: por una parte, Francis Bacon, con su obra Novum Organum, y, René Descartes, con su Discours de la méthode. El triunfo del empirismo desplazó la mirada hacia una nueva imagen del hombre, aunque en el caso de Descartes fuera visto con algo más de escepticismo que por el filósofo inglés. Por otra, con cierta distancia temporal, resulta clave Friedrich Nietzsche y su Also sprach Zarathustra, por su amplitud y profundidad nihilista, aunque también me gusta relacionar esta obra con Die fröhliche Wissenschaft, por significar el cierre de la etapa crítica del autor con la metafísica.

\subsection{La modernidad ampliada: decadencia a espaldas del ser humano}

Actualmente, el hombre tecnológico se encuentra inserto en una modernidad ampliada consistente en una época caracterizada por varios de los rasgos de la vieja modernidad, como el individualismo y el capitalismo radicales y feroces, dentro de un contexto tecnológico. De un lado, radical, por el giro extremo y abrupto que se ha producido en la relación del ser humano con la tecnologia; de otro, feroz, por lo despiadada y agresiva que se ha vuelto la relación del ser humano con el mercado. Se ha hecho patente la vieja dicotomía del estás conmigo o estás contra mí. El ser humano parece que tiene que decidir si situarse en una posición favorable a la tecnologia y al capitalismo, o pasar a convertirse en uno de sus enemigos. Suscribir una postura crítica frente al mal uso y a la clara dependencia de la tecnología o a la obsesiva mirada hacia el economicismo, no significa que reneguemos de la tecnologia ${ }^{8}$ o dejemos de participar del bienestar que procura en ciertas parcelas estar insertos en el capitalismo; al contrario, consiste en poner de relieve la crisis que acontece en el tratamiento de las relaciones humanas. Esto se traduce en una falta de respeto e, incluso, de desprecio hacia el ser humano. Tampoco hay que dejar de lado que la relación del ser humano con el individualismo y el capitalismo resultan, de momento, inevitables en las sociedades altamente desarrolladas, aunque nosotros sí podemos decidir hasta cierto punto cómo y de qué manera nos relacionamos con ambos, de acuerdo, entre otros elementos, con el estatus en el que nos encontramos y al margen de actuación que cada uno posea dentro del sistema. No es cuestión de pretender que adinerados abogados, artistas, banqueros, deportistas, empresarios, por citar algunos ejemplos, vivan de forma

8 Por ello, coincidimos con Ballesteros en la crítica a la posición apocalíptica, romántico-anarquista, que "desearia rechazar en bloque el factor tecnológico, considerado como encarnación del mal, para volver a la sociedad preindustrial”, Jesús BALlesteros, "Estudio introductorio”, en Sergio CoTTA, Itinerarios humanos del derecho, Pamplona, EUNSA, estudio introductorio y trad. de J. Ballesteros, 1974, p. 13. 
miserable o con considerables restricciones en sociedades similares a la nuestra, sino con sobriedad de acuerdo con el estatus social en el que se encuentran y, por supuesto, no a costa del sufrimiento de los demás. Decir esto es un planteamiento idealista pero puede dar qué pensar sobre una forma de actuar.

Una modernidad ampliada entendida como proyecto inacabado, ${ }^{9}$ de ahí que no utilicemos otros términos como el de posmodernidad (como ese momento final de la modernidad) o transmodernidad (como superación de aquel modelo por obsoleto). No consideramos, sin embargo, del todo desacertadas las posturas que hablan de ruptura, pero preferimos hablar de continuum desde el plano de la historia de las ideas debido a las semejanzas entre la vieja y la nueva modernidad. Por consiguiente, referirse a la modernidad ampliada como proyecto inacabado puede tener sentido a riesgo de producir cierta confusión: los ropajes son distintos pero los problemas de fondo y las tendencias resultan similares, a pesar de los cambios de escenario y actores. Una modernidad ampliada que da lugar a una nueva religión reduccionista y materialista de la que es dificil escapar y mantenerse al margen. Esta realidad se ve propiciada en un mundo globalizado debido al papel desempeñado por la "industria actual" creada "para producir atracciones y tentaciones en esta carrera en pos de deseos nuevos". ${ }^{10}$

La modernidad ampliada presenta un deliberado acento estético, al menos, por dos razones: la primera, porque se vive en un mundo de las apariencias. Un mundo atrapado en las imágenes: se habla de globalización pero el mundo está falsamente globalizado. ${ }^{11}$ Bauman señala, con razón, que el sello de la "globalización negativa" está impreso en el nuevo individualismo, en el debilitamiento de los vínculos humanos y en el languidecimiento de la solidaridad. ${ }^{12}$ La segunda se centra en las constantes dicotomías presentes: reflexionamos para reducir la corrupción y nos toca empaparnos de constantes actitudes corruptas; nos preguntamos sobre la crisis de las ideologias y no vemos más que reproches entre los partidos políticos. Dos ideas que son reflejo de una misma problemática: la confusión del ser con el parecer o el aparentar, en este mundo de las apariencias y, sobre todo, de las imágenes.

El paralelismo sostenido entre la vieja y la nueva modernidad se detecta por la presencia de rasgos comunes como los ya mencionados, aunque cabría destacar

9 Es compartida la idea de Habermas de la modernidad como proyecto inacabado, Jürgen HABERMAS, Der Philosophische Diskurs der Moderne (1985). Citamos por la edición española El discurso filosófico de la modernidad, Madrid, Taurus, trad. de M. Jiménez Redondo, 1993, p. 9.

10 Zygmunt Bauman, Postmodernity and its Descontents (1997). Citamos por la edición española, La posmodernidad y sus descontentos, Madrid, Akal, trad. de M. Malo de Molina Bodelón y C. Piña Aldao, 2009, p. 105.

11 Claro está, existen aspectos positivos como la mejora de la esperanza de vida, la disminución de la desnutrición y de las grandes guerras, entre otros; sin embargo, los ricos son más ricos, no se ha erradicado la pobreza, los conflictos armados no cesan, la pena de muerte todavía persiste, la cosificación del ser humano ha crecido enormemente, etc.

12 Zygmunt Bauman, Liquid Times. Living in an Age of Uncertainty (2007). Citamos por la traducción española de. Tiempos líquidos. Vivir en una época de incertidumbre, $3^{\mathbf{a}}$ ed., Barcelona, Tusquets Editores, trad. C. Corral Santos, 2010, p. 40. 
otro: la actual revolución tecnológica, que presenta semejanzas con la primera y segunda revolución industrial. La primera, tal y como hiciera la revolución industrial, está creando sus instituciones civiles nuevas para organizar su actividad: "Grandes corporaciones y agentes que dominan Internet" y "organizaciones y movimientos que los responden en su misma lengua: el código de la Red". ${ }^{13}$ Igualmente, una mejora tecnológica que creó riqueza y trajo bienestar económico, pero que hizo demasiado hincapié en lo material y desatendió en buena medida los estándares éticos.

Una consecuencia de ello es la proliferación de las sociedades del low cost, de los anhelos frustrados y de las miserias contenidas, que no respetan al prójimo y que en el fondo no se respetan a sí mismas. Frente a ello debe alzarse un pensamiento crítico y constructivo apartado del discurso plano, acomodaticio $\mathrm{y}$ falseador de la realidad, al igual que una actitud debidamente reflexiva sobre el tiempo presente.

\subsection{Crisis de la razón jurídica en tiempos de democracia}

La modernización, según Ballesteros, presenta como notas centrales el individualismo y el cuantitativismo, siendo ambas insuficientes para luchar contra la realidad de la marginación. ${ }^{14}$ Frente a la indiferencia individualista y al despilfarro consumista surge lo que el autor llama posmodernidad como resistencia consistente en una postura integradora que no reniega de la razón, el progreso y la democracia, empeñándose en resistir contra la injusticia, el cretinismo y la inhumanidad creciente de nuestro mundo con la mirada puesta en la lucha a favor de la paz. ${ }^{15}$ Una postura que puede ayudar a encauzar o, por lo menos, hacer critica a la modernidad ampliada en la que se vive. No obstante, quizá el autor se queda corto al no explicitar más el que puede considerarse, en este contexto, el concepto más importante de los tres: el de razón. No se trata de un retorno a una razón natural, relegada exageradamente al baúl de las antiguallas, para el acceso al conocimiento, ni tampoco quedarse deslumbrados por el "imperialismo de la razón tecnológica”. ${ }^{16}$ Resulta plausible una crítica a la confianza excesiva en la naturaleza teologal como a la ideología del progreso inevitable, propia de la modernización tecnocrática, para hacer hincapié en el potencial de la razón jurídica y, sobre todo, de la razón humana. Esa visión del progreso por el progreso con el fin de alcanzar la perfección de la sociedad, al igual que la crisis de las ideologias surgida en relación con el derecho, ha hecho que la razón humana y la jurídica estén en crisis. Una revitalización de lo mejor de la razón humana que pasa por revalorizar y refundar la categoría de ser humano, por un lado, y de la razón jurídica para reducir la hiperinflación normativa y hacer más hincapié en una visión

13 Enrique Alonso, El nuevo leviatán. Una historia política de la Red, Madrid, Diaz \& Pons, 2015, pp. 7 y 8 .

2014 Jesús Ballesteros, Postmodernidad, op. cit., p. 43.

15 Ibid., p. 13.

16 Andrés OlLERo, "La crítica de la razón tecnológica. Benedicto XVI y Habermas, un paralelismo sostenido", en Anales de la Real Academia de Ciencias Morales y Políticas 87 (2010), p. 438. 
jurídica verdaderamente garantizadora e integradora de la debilidad del ser humano, por otro. Todo ello nos puede hacer pensar en un cambio de rumbo, aunque seguramente hayamos llegado tarde en el tiempo, para enmendar la situación a corto y a medio plazo.

La crisis de la razón jurídica ha venido acrecentada por una visión puramente instrumental del derecho desde la cual —según Ballesteros- este carece de valor por sí mismo, de finalidad intrínseca alguna, siendo solo una "pura herramienta al servicio de la utilidad social, al servicio de la economía”. ${ }^{17}$ Una visión perturbadora que parece degenerar en simple materialismo. Así, cobra sentido su crítica anticipadora de la época actual:

La inalienabilidad de los derechos aparece hoy día especialmente relevante para hacer frente a los peligros del "totalitarismo light", unidos a la reducción del ser humano al homo oeconomicus, y que no ve nada inconveniente en ofender la dignidad de la persona, si cuenta con el consentimiento del ofendido y por ello apoya la venta de la intimidad en los diversos medios de comunicación. ${ }^{18}$

Comparto su crítica y suscribo una visión pesimista (que no fatalista) del papel salvador que pueda desarrollar el derecho en la época actual, sin ser suficiente para mejorar en no pocos casos la situación presente. Los Estados constitucionales de derecho han renunciado a uno de sus principios básicos como es la férrea protección de los vulnerables, al no defender suficientemente al ser humano que se encuentra en situación de debilidad. Esa es precisamente la situación que ha fomentado el individualismo capitalista, fruto del cual el derecho se encuentra cada vez más al servicio de intereses mercantilistas hasta el punto de hacer prevalecer los intereses de los fuertes sobre los débiles. Según Ballesteros, resulta clave invertir las tornas para recuperar el ordoliberalismo a partir del cual la economía de mercado se desarrolle en una sociedad no mercantilizada, siendo imprescindibles las virtudes sociales como el trabajo, la responsabilidad, la sobriedad y la solidaridad para la consecución de este objetivo. ${ }^{19} \mathrm{El}$ establecimiento de limites al poder del mercado debe ser una constante presente en la mentalidad de los gobernados $\mathrm{y}$, sobre todo, de los gobernantes, por ser un fin que se debe tener en cuenta en toda democracia. En este sentido, internet ha supuesto un lugar perfecto para el desarrollo de los monopolios y los oligopolios. Tal es así, que se ha llegado a un punto en el que, según Bauman, la "economía” se libera poco a poco de todo control politico, en buena medida motivada por "la difusión ilimitada e irrefrenable de las normas de libre comercio y, sobre todo, al movimiento sin trabas del capital

17 Jesús Ballesteros, "En torno al sentido del derecho en la actualidad", en Verdad y vida, tomo XXXV (1977), p. 448. Similares afirmaciones en Sobre el sentido del derecho. Introducción a la filosofia jurídica (1984), $3^{\text {a }}$ ed., Madrid, Tecnos, 2011, p. 179.

18 Epílogo titulado "Posmodernidad y tercer milenio" (2000), incluido en la $2^{\mathrm{a}}$ ed. de Jesús Ballesteros, Postmodernidad, op. cit., p. 177.

19 Jesús Ballesteros, "Contra la financiarización de la economía y la mercantilización de la sociedad", en Anuario da Facultade de Dereito da Universidade da Coruña 17 (2013), p. 64. 
y las finanzas”. ${ }^{20}$ Una razón más que invita a desarrollar los planteamientos de Ballesteros con la mirada puesta en recuperar la sobriedad como forma de vivir, el trabajo bien hecho en las pequeñas cosas, el sentido de la responsabilidad y la solidaridad con nuestros congéneres.

\section{EL HOMBRE TECNOLÓGICO Y SU DEVOCIÓN INDIVIDUALISTA Y CAPITALISTA}

A lo largo de la historia del pensamiento, la imagen del hombre ha ido variando y ha coincidido, en no pocas ocasiones, con grandes periodos históricos. Así, en la Antigüedad, la imagen del hombre era la del sabio, con su elitismo por conocimientos, unido a su posición social. En la Edad Media, sin embargo, el hombre no se entendía sino era por su unión con Dios basada en una antropología cristiana. En la Ilustración, el hombre se alzaba como técnico de los saberes con lo que daba comienzo el segundo despertar de la filosofia, un intento de romper con la referencia a Dios, mostrando un hombre calculante que, en palabras de Kant, sale de su "minoría de edad culpable". ${ }^{21}$ Una entrada en la modernidad con "la certeza de que el futuro será mejor que el pasado y el presente, la certeza de que el futuro más o menos lejano coincide con la plenitud". ${ }^{22}$ Quedaba patente la idea de que se podía soñar con un mundo en el que la tecnologia posibilitase una vida en sociedad enormemente más feliz que la actual.

\subsection{La nueva imagen del hombre: un ser casi aislado y poco comunicativo}

En estos momentos nos encontramos en la era del hombre tecnológico, yendo más allá del hombre meramente económico, propiciada entre otros factores por las nuevas tecnologías y formas de comunicarse en red, así como por el crecimiento del individualismo capitalista aparejado a situaciones de mayor bienestar no debidamente universalizado. El hombre tecnológico, convertido en individualista y capitalista, queriéndolo o no, utiliza las posibilidades que le otorga la comunicación y se sirve del capitalismo, ejerce de comunicador y de mercenario, a través de una vida que otorga más posibilidades de hacer, pero no necesariamente mejor. Es un hombre casi aislado, individualista en el fondo y colectivista en las formas; esto es, tremendamente comunicado pero poco comunicativo.

Por tanto, no se puede entender el hombre sin referencia a la tecnologia, sus ropajes son —nos guste o no- inevitablemente tecnológicos. Según Ballesteros, la importancia cada vez más creciente de las nuevas tecnologias informáticas supone "una manifestación de fenómeno contrario a la entropía", lo que aumenta "las

20 Zygmunt Bauman, Globalization. The Human Consequences (1998). Citamos por la edición española Globalización. Consecuencias humanas, México, Fondo de Cultura Económica, trad. de D. Zadunaisky, 2004, p. 89.

21 Immanuel KANT, "Beantwortung der Frage: Was ist Aufklärung?", en Berlinische Monatsschrift, diciembre (1784), p. 481.

22 Jesús Ballesteros, Postmodernidad, op. cit., pp. 35 y 36. 
posibilidades de comunicación entre los seres humanos" y favorece "la unidad del género humano con un mínimo de coste energético". ${ }^{23}$ Eso significa que, en buena medida, se produce una relación ambivalente: por un lado, el hombre se alimenta de la tecnologia y, por otro, la tecnologia se alimenta del hombre. Una retroalimentación de tal calibre en un primer momento nos enriquece, al aumentar nuestras posibilidades de hacer cosas con los beneficios que ello conlleva, pero a la postre nos empequeñece y nos embrutece en relación con el trato hacia nuestro semejante. Este panorama contribuye a crear una "Tierra plana" en la que una buena parte estamos conectados - de una u otra manera y en mejor o peor medida - gracias a las nuevas tecnologias, lo que también nos convierte en "seres humanos planos". En términos más claros: el estar comunicados con gente de medio mundo también ha hecho que no haga tanta falta comunicarnos personalmente con nuestros congéneres, empobreciendo el diálogo cara a cara.

La imagen del nuevo hombre es tecnológica e individualista, cimentada en los pilares del relativismo cultural imperante. Más perjudicial que el relativismo sería el nihilismo del posliberalismo por su indiferencia hacia el prójimo. Sus perversas consecuencias nos han llevado, con ayuda de la tecnología, a una situación de decrepitud en la forma de relacionarnos con nuestros semejantes. Algunos de los factores, en continua sinergia, de la penosa deriva de la imagen actual del hombre son explicitados por Serna:

Un sistema educativo fuertemente mecanicista y constructivista combinado con un sistema de ocio que fomenta la pasividad a través de la cultura de lo audiovisual; esta combinación es en gran medida responsable de que nos estemos convirtiendo en personas y ciudadanos que no piensan, que aceptan de forma casi acrítica lo que viene impuesto por la denominada opinión pública, que no es más que la opinión de unos pocos publicada en los medios de comunicación de masas, controlados a su vez por quienes manejan los hilos del poder: una lamentable alianza de empresarios de la comunicación, [obsesionados por] ganar dinero aumentando la audiencia [...] y de políticos que han olvidado también los principios, los ideales, los fines, para concentrarse exclusivamente en los medios [como son] la obtención, el mantenimiento y el incremento del poder, cuando no el propio enriquecimiento personal. ${ }^{24}$

Unas imágenes sin imaginación (sin verdadera profundidad), que han fraguado toda una cultura de lo visual convertida en instrumento de socialización. La transmisión del conocimiento ha pasado de ser escrita a ser visual, de lo teórico a lo práctico, donde lo verdaderamente útil es ganar dinero. Se hace dificil traducir esa hermenéutica de las imágenes a un lenguaje minimamente coherente. Cada vez las imágenes son más poderosas que los argumentos. Un fuerte componente cultural de carácter estético atravesado por la tecnología y la economía. Eso es, un mundo altamente tecnificado y economizado en el que impera la ideología tecnológica y utilitarista, estando las relaciones entre los seres humanos cada vez más mercantilizadas. 


\subsection{Decadencia y mercantilización de las relaciones humanas}

Voces disonantes muestran un descontento, más o menos generalizado, acerca de la decadencia de los valores éticos, jurídicos y culturales en relación con la humanidad; ${ }^{25}$ cuestión distinta es que no sea tan fácil dotar de contenido a ambos sin caer en versiones reduccionistas. Nuestros valores están influidos por la sociedad que nos ha tocado vivir. Por tanto, si nuestra sociedad es decadente, resulta más posible que nuestros valores se encuentran marcados por el signo de la decadencia. Cobra fuerza el antivalor de enriquecernos y de acumular bienes a toda costa, que en el fondo para algunos es un valor pero de tipo utilitarista y hedonista. Las generaciones actuales deben aprender de las generaciones pasadas y no solo del tiempo que les ha tocado vivir. No obstante, podemos afirmar, con seguridad, que la situación actual empobrece las relaciones humanas. El empobrecimiento se produce desde el momento en que no se cumplen suficientemente algunos de los presupuestos más básicos de un Estado constitucional de derecho como son la protección de los más vulnerables y el freno a las acciones de los fuertes frente a los débiles. Por su parte, Ollero ya propugnaba un conocimiento histórico y práctico de raíz coexistencial y de influencia cottiana, en el que el individuo no sea un ser aislado en sí mismo, al contrario, sea un ser-con-los-otros. ${ }^{26} \mathrm{~A}$ la vista de la época actual, nos conformariamos con que no se viviera de espaldas a los demás ni a costa de su sufrimiento. El respeto y la igualdad politica de todos los seres humanos con la mirada puesta en la supervivencia de la humanidad y no en su autodestrucción.

La reflexión acerca de conceptos como valor, derecho y humanidad nos lleva a destacar la posmodernidad como resistencia que pretende "resistir contra la injusticia, inhumanidad y cretinismo creciente de nuestro mundo y coloca como metas fundamentales la lucha a favor de la paz y en contra de los bloques militares, la defensa de la frugalidad ecológica contra el despilfarro consumista y de la solidaridad ecuménica contra la indiferencia individualista”. ${ }^{27} \mathrm{Su}$ visión para erradicar parte de los problemas del mundo actual (el hambre, la miseria y los conflictos armados, entre otros) pasa por una postura contraria al nihilismo y a la deep ecology. En contraposición, se alza la posmodernidad como decadencia, la cual ha recibido un significativo impulso del movimiento de lo "políticamente correcto", y aparece de manera clara en contra de toda pretensión de universalidad, que es juzgada como resultado de un etnocentrismo occidental intolerante e intolerable. ${ }^{28}$ Cabría matizar que sí hay algo de etnocentrismo cultural en Occidente

25 Ballesteros no es muy optimista sobre el curso de los acontecimientos: "Lo que parece indudable es que la creencia en la mitologia posthumanista puede preparar la ruina de la humanidad”, Jesús Ballesteros, "Biotecnología, biopolítica y posthumanismo", en Jesús Ballesteros y Encarnación FERnández (coords.), Biotecnología y posthumanismo, Cizur Menor, Aranzadi, 2007, p. 46.

26 Cfr. Andrés Ollero, ¿Tiene razón el derecho? Entre método científico y voluntad politica (1996). Prólogo de Gregorio Peces-Barba, 2ª ed., Madrid, Congreso de los Diputados, 2006, pp. 210 y 303, entre otras.

27 Jesús Ballesteros, Postmodernidad, op. cit., p. 13.

28 Ibid., p. 161. 
que nos impide conocer, o mejor dicho, reconocer realidades diversas a la nuestra. Los ciudadanos occidentales debemos pensar en ir haciéndonos en la diferencia con Oriente y América Latina, aunque sin admitir el fanatismo y la violencia. Esta posmodernidad decadente condiciona de forma indefectible a la humanidad y al derecho; esto es, el sentido antropológico y la determinación del derecho. Frente a esta decadencia que acontece parece ser conveniente resaltar la paridad ontológica de la persona de la que nos habló Cotta, ya que el ser humano necesita de otros para reafirmarse como tal. Ahora bien, retomar la importancia del concepto de alteridad lleva a establecer una conexión fuerte entre derecho y vida humana con el fin de conseguir, "no la perfección de la realización personal del hombre, lo que corresponde a la moral, pero sí un estadio importante al servicio de tal perfección". De ahí que el derecho venga "a institucionalizar la fidelidad humana en cuanto afecta a terceros". ${ }^{29}$

\section{NATURALEza humana Líquida Y LA NUEVA ERA DE LAS MÁQUINAS}

La forma estable y determinada de la naturaleza aristotélica, ${ }^{30}$ al igual que la confianza medida del pensamiento ilustrado en la naturaleza humana producto de los humanistas del Renacimiento, ha quedado desplazada en el siglo XXI por una tecnociencia que busca una nueva fijación del concepto de naturaleza. ${ }^{31}$ En la actualidad se ha producido un cambio de paradigma respecto al concepto de naturaleza humana a raíz, en buena medida, de la secuenciación del genoma humano en el 2001. Esto hace replantearnos si realmente "la naturaleza humana no es una entelequia etérea, sino que está anclada en la realidad robusta del genoma”. ${ }^{32}$ Por ello, no cabe dejar de lado aquella visión crítica expuesta por Jonas acerca de la tremenda vulnerabilidad de la naturaleza sometida a la intervención técnica del hombre. ${ }^{33}$ La vida está fragmentada y, por ende, la naturaleza humana también. La incertidumbre hacia una realidad de tal calado pone de relieve la fragilidad y el carácter líquido de la naturaleza humana, como ya señalara Bauman para la modernidad; no obstante, aquí nos interesa destacar no solo que la

29 Jesús Ballesteros, "En torno al sentido del derecho en la actualidad", op. cit., p. 458.

30 Cfr. Aristóteles, Metafisica, Estudio introductorio, análisis de los libros y revisión del texto de F. Larroyo, México, Porrúa, 1978, libro VII, cap. 1, pp. 111-112. En consecuencia, tal y como "se llama 'arte' a lo que es conforme al arte, es decir, a lo artístico, así también se llama 'naturaleza' a lo que es conforme a la naturaleza, esto es, a lo natural", Aristóteles, Física. Libro I-II, Buenos Aires, Biblos, trad., introducción y comentario de M. D. Boeri, 1993, p. 75, 193a.

31 Es determinante la intención de no acabar con la naturaleza humana, para no llegar al demoledor diagnóstico de Negro Pavón: "Discutida o arruinada la idea de una naturaleza humana fija y constante como un hecho del que hay que partir, el relativismo tiende a convertirse en un absoluto y el pensamiento necesariamente en ideologia”, Dalmacio Negro, El mito del hombre nuevo, Madrid, Encuentro, 2009, p. 199.

32 Jesús Mosterín, La naturaleza humana, 5 $5^{\mathrm{a}}$ ed., Madrid, Espasa Calpe, 2006, p. 12. También, p. 11. Para una visión diferente y más inclusiva que la de Mosterín, cfr. José Antonio SANTos, Los olvidados del nacionalsocialismo, cit., especialmente, pp. 159-186.

33 Hans Jonas, Das Prinzip Verantwortung (1979). Citamos por la edición española Hans Jonas, El principio de responsabilidad. Ensayo de una ética para la civilización tecnológica, $2^{\text {a }}$ ed., Introducción de A. Sánchez Pascual, Barcelona, Herder, trad. de J. Mª . Fernández Retenga, 2004, p. 33. 
nueva modernidad y la naturaleza humana son líquidas, sino más ampliamente que los tiempos son liquidos. ${ }^{34}$

La naturaleza humana líquida opera actualmente en el terreno de una modernidad ampliada, rupturista con buena parte de lo mejor de nuestro pasado reciente, que tiene como uno de sus escenarios paradigmáticos la manipulación genética. Tal es así que "las posibilidades abiertas por la investigación y por la práctica clínica desbordan aquel marco normativo que fue definido en la posguerra”. ${ }^{35}$ La verdadera preocupación no radica en que esa normativa ya no responda a las necesidades de los tiempos modernos, sino de manera más profunda que la prosa de la posguerra haya sido olvidada. Cabe pensar que la naturaleza humana no debería ser tratada como material líquido y abogar por entenderla como aquel programa de perfeccionamiento de un ser libre ${ }^{36}$ que incluye una serie de elementos comunes debido a factores genéticos y al medio en el que este se desenvuelve, a pesar de que varios de los elementos que identificaban al ser humano vivo hubieran perdido fuerza por el mero avance de la ciencia. Por fortuna, todavía sigue en pie como característica propia del ser humano su dignidad. En este contexto tecnológico, Habermas distingue entre la preocupación de los alemanes por conceptos normativos de persona o concepciones metafísicas de la naturaleza, que hacen hincapié en el "sî" del futuro desarrollo de la técnica genética, mientras que los norteamericanos lo hacen más en el "cómo" llevarlo a la práctica, sin ponerlo en cuestión pese a que empuje hacia un shopping in the genetic supermarket. ${ }^{37}$ En el pensamiento occidental triunfa de forma clara la segunda versión centrada en el interés por dominar la naturaleza que, a través de los avances tecnológicos, posibilitaría la cura de graves enfermedades, la disminución considerable de las guerras y el poder estar más y mejor comunicados e informados. Semejante manera de pensar refleja una concepción transhumanista fundada en un intento de superación, gracias a la tecnociencia, de aquello que caracteriza al ser humano: el sufrimiento, la enfermedad e, incluso, la muerte. A dia de hoy, el proyecto no se ha completado plenamente, pero el sueño sigue presente. Con razón vaticina Bauman: "El día de 'hoy' no es más que una premonición rudimentaria del mañana; o, antes bien, su reflejo menor, desfigurado. Lo que es queda cancelado de antemano por lo que ha de venir, pero extrae su significación y su sentido - su único sentido- de esta cancelación”. ${ }^{38}$

La actual imagen del hombre aparece claramente unida a la de la tecnología ciborg, que supone en sí bastante más que realizar un trasplante de corazón o implantar una prótesis biónica a un miembro amputado. Estoy refiriéndome a la singulari-

34 Zygmunt Bauman, Tiempos líquidos, op. cit., 169 pp.

35 María Teresa López De la Vieja, La pendiente resbaladiza. La práctica de la argumentación moral, Madrid y México D.F., Plaza y Valdés, 2010, p. 14.

36 Para Aristóteles "el Ser se entiende de lo que es accidentalmente o de lo que es en sí" en ese juego entre potencia y acto. ARISTóteles, Metafisica, op. cit., libro V, cap. 7, p. 83. edición ampliada, Frankfurt am Main, Suhrkamp, 2002, p. 128.

38 Zygmunt Bauman, La posmodernidad y sus descontentos, op. cit., p. 92. 
dad tecnológica como la posibilidad de que en un futuro las máquinas tengan capacidad de autoarreglarse; momento en que la inteligencia artificial podrá superar a la inteligencia humana y conformar un nuevo concepto de naturaleza humana. El significado de fondo es mucho más extenso: cambiar la sociedad por medio de la transformación de la naturaleza humana y la imagen del hombre.

En esta modernidad ampliada, la solución al futuro de la humanidad pasa erróneamente por una enorme confianza en las posibilidades de las nuevas tecnologias para superar las limitaciones biológicas. Ballesteros destaca con razón que el "complejo de inferioridad del ser humano ante lo no personal, ante la máquina, que se había iniciado con el futurismo se manifiesta ahora como complejo de inferioridad ante la información”. El proceso de transformación se inicia levemente por el deslumbramiento ante el ordenador por su "mayor velocidad" y "exactitud" en la forma de procesar la información "y se afirma que la naturaleza son hoy las bases de datos y se acaba reduciendo la humanidad a simple información genética y o electrónica de modo tal que todo lo humano se vuelve capaz de manipulación". ${ }^{39}$ Es un tanto ingenuo pensar que utilizar la tecnología para el mejoramiento de los seres humanos traerá solamente cosas buenas, pero ya solo pensar de esa manera nos produce preocupación. Debemos romper con la lógica discursiva que juega con las proyecciones ilimitadas del hombre tecnológico. Es un problema de límites y de las intenciones que conllevan las decisiones que se tomen. En esencia, se detecta una visión futurista y eugenésica centrada en el perfeccionismo que pretende dominar la naturaleza a través de la utilización de las máquinas y la información genética.

Ante semejante panorama, Ballesteros presenta su posmodernidad resistente, desde una visión un tanto pesimista, para abogar por unas relaciones entre el ser humano y la naturaleza a partir de "la conciencia de la excelencia humana, en cuanto ser capaz de salir de sí mismo y cuidar de los otros". El objetivo no es otro que dar sentido al modo de concebir la "otredad", para dejar de ser considerado el otro como extraño y hostil. ${ }^{40}$ Desgraciadamente, en los últimos actuales, resulta complicado verlo desde una particular excelencia humana que haga al ser humano verdaderamente acreedor de tal condición, consciente de su naturaleza, de ayudar a los demás, pero sobre todo de cuidarlos.

\section{CONCLUSIONES}

Como hemos intentado reflejar, la modernidad ampliada es una nueva modernidad que en aspectos cruciales se parece a la vieja: el culto al individuo, al consumismo y a un mal entendido racionalismo en sus facetas más radicales, que propicia hablar de un nuevo ser humano marcado por los cambios tecnológicos

39 Jesús Ballesteros, "Más allá de la eugenesia: el posthumanismo como negación del homo patiens",

40 Jesús Ballesteros, Postmodernidad, op. cit., pp. 176 y 172, respectivamente. 
y que, en sí, es un ser tecnológico. La creencia en una imagen del hombre nueva y tecnológica, atravesada por el tener y el poseer, más que por el ser y el saber. Una imagen del hombre falseadora y decadente a partir de la cual se piensa que el presente es indefectiblemente mejor que el pasado reciente, aunque peor que el soñado futuro próximo.

La entrada en la era tecnológica supone una nueva época que perfectamente se puede calificar de decadente en términos éticos y jurídicos. Una modernidad ampliada que lleva aparejada una imagen del hombre como ser tecnológico, siendo uno de sus rasgos definitorios el individualismo capitalista característico también de la vieja modernidad, aunque con otro eje de coordenadas. Una ética jurídica del débil puede ayudar a frenar los desmanes de una época marcada por la manipulación genética y, en general, por la instrumentalización del ser humano y el empobrecimiento de las relaciones humanas.

La degradación de los valores ya mencionados ha inclinado la balanza hacia los de carácter estético y económico. Por esta razón, puede ser conveniente pensar en una ética jurídica del débil que replantee la confianza desmedida en la relación futura entre tecnologia y ser humano al servicio de intereses mercantilistas, con el objetivo de que las necesidades de los débiles no acaben disueltas por los intereses de los fuertes. Ballesteros ha participado activamente de esta lucha comprometida con la finalidad de repensar el tiempo presente y en su decidido interés por pensar en los demás a través de su posmodernidad como resistencia.

Quizá para algunos puede calificarse de fatalista el discurso trazado, aunque para otros sea tildado de realista; en sí hemos intentado plasmar un pesimismo contenido. El tiempo oportuno para reconducir esta situación a medio plazo ha terminado; no obstante, el empeoramiento de las relaciones humanas con nuestros semejantes no significa la imposibilidad de seguir teniendo confianza en el ser humano o de conseguir determinadas mejoras en el nivel de bienestar respecto de la situación actual. Significa el triunfo de la sinrazón y el empobrecimiento de las relaciones con nuestro congéneres. Un final feliz para nuestra historia presente resulta dificilmente calculable, tan siquiera imaginable, pero de una manera o de otra los avances tecnológicos en esta nueva era de las máquinas jugarán un papel crucial en el dominio de la naturaleza ya líquida.

Esta época de decadentismo mejorará, teniendo en cuenta que todos los periodos son cíclicos, pero no sé si lo verán las generaciones actuales al estar en el inicio de este cambio de paradigma. Mientras tanto, ¿qué podemos hacer? Es preciso realizar una lucha continua por recuperar el rigor en el quehacer diario y el compromiso con el tiempo presente. No se trata de una vuelta a los orígenes, sino de retomar lo más aprovechable de nuestra mejor tradición, trayendo al presente lo mejor de aquel momento pasado: la prudencia, el sano inconformismo y, sobre todo, el respeto. En definitiva, una reconsideración del saber universal de la filosofia y, en general, una visión humanista del mundo que ayude a tener en cuenta la virtud de la sobriedad en el modo de vivir, el valor del trabajo que conlleva sacrificio, la recuperación de la actitud responsable y la solidaridad con nuestros iguales. 


\section{BIBLIOGRAFÍA}

Alonso, Enrique, El nuevo leviatán. Una historia politica de la Red, Madrid, Díaz \& Pons, 2015.

ARISTóteles, Metafisica. Estudio introductorio, análisis de los libros y revisión del texto de F. Larroyo, México, Porrúa, 1978.

Aristóteles, Física. Libro I-II, Buenos Aires, Biblos, trad., introducción y comentario de M. D. Boeri, 1993.

Ballesteros, Jesús, La filosofia jurídica de Giuseppe Capograssi, Roma-Madrid, CSIC, 1973.

Ballesteros, Jesús, "Itinerarios humanos del derecho. Sergio Cotta", en Persona y Derecho 1 (1974), pp. 639-644.

Ballesteros, Jesús, Postmodernidad: decadencia o resistencia, 2ª edición, Madrid, Tecnos, 2000.

Ballesteros, Jesús, "Biotecnología, biopolítica y posthumanismo", en Jesús BALLESTEROS y Encarnación FERnÁNdEZ (coords.), Biotecnología y posthumanismo, Cizur Menor, Aranzadi, 2007.

Ballesteros, Jesús, Sobre el sentido del derecho. Introducción a la filosofia jurídica (1984), 3aㅡ ed., Madrid, Tecnos, 2011.

Ballesteros, Jesús, "Más allá de la eugenesia: el posthumanismo como negación del homo patiens", en Cuadernos de bioética 77 (2012), pp. 15-23.

Ballesteros Jesús, "Contra la financiarización de la economía y la mercantilización de la sociedad”, en Anuario da Facultade de Dereito da Universidade da Coruña 17 (2013), pp. 55-68.

Bauman, Zygmunt, Globalización. Consecuencias humanas, México, Fondo de Cultura Económica, trad. de D. Zadunaisky, 2004.

Bauman, Zygmunt, La posmodernidad y sus descontentos, Madrid, Akal, trad. de M. Malo de Molina Bodelón y C. Piña Aldao, 2009.

Bauman, Zygmunt, Tiempos liquidos. Vivir en una época de incertidumbre, $3^{\text {a }}$ ed., Barcelona, Tusquets Editores, trad. de C. Corral Santos, 2010.

Habermas, Jürgen, El discurso filosófico de la modernidad, Madrid, Taurus, trad. de M. Jiménez Redondo, 1993.

Habermas, Jürgen, Die Zukunft der menschlichen Natur. Auf dem Weg zu einer liberalen Eugenik?, 4ª edición ampliada, Frankfurt am Main, Suhrkamp, 2002.

Jonas, Hans, El principio de responsabilidad. Ensayo de una ética para la civilización tecnológica, 2ª ed., Introducción de A. Sánchez Pascual, Barcelona, Herder, trad. de J. Mª ${ }^{a}$. Fernández Retenga, 2004.

Julios Campuzano, Alfonso de, "Individualismo y modernidad. Una lectura alternativa”, en Anuario de filosofia del derecho XII (1995), pp. 239-268. 
KANT, Immanuel, "Beantwortung der Frage: Was ist Aufklärung?", en Berlinische Monatsschrift, diciembre (1784), pp. 481-494.

López De la VIEJA, María Teresa, La pendiente resbaladiza. La práctica de la argumentación moral, Madrid y México D.F., Plaza y Valdés, 2010.

Negro, Dalmacio, El mito del hombre nuevo, Madrid, Encuentro, 2009.

Ollero, Andrés, ¿Tiene razón el derecho? Entre método científico y voluntad política (1996). Prólogo de Gregorio Peces-Barba, 2a ed., Madrid, Congreso de los Diputados, 2006.

Ollero, Andrés, "La crítica de la razón tecnológica. Benedicto XVI y Habermas, un paralelismo sostenido", en Anales de la Real Academia de Ciencias Morales y Políticas 87 (2010), pp. 435-451.

SANTos, José Antonio, Los olvidados del nacionalsocialismo. Repensar la memoria, Madrid, Centro de Estudios Políticos y Constitucionales, 2014.

SERna, Pedro, "Politica posmoderna y crisis de la razón jurídica", en Anuario da Facultade de Dereito da Universidade da Coruña 13 (2009), pp. 1079-1096. 